\title{
The Voice: novas formas de participação e interação na segunda tela
}

Daiana Sigiliano ${ }^{1}$ e Gabriela Borges ${ }^{2}$ Fora e colaboradora do Centro de Investigação em Artes e Comunicação da Universidade do Algarve, Portugal. 


\section{Resumo}

A Social TV está transformando as métricas da audiência, o nível de participação dos interagentes, as estruturas narrativas, a recepção do telespectador, e trazendo de volta o appointment television. O fenômeno mostra que o atual ecossistema de conectividade não representa a sentença de morte para o mass media, mas uma oportunidade de se atualizar diante dos novos hábitos dos telespectadores multitasking. Com o intuito de realizar uma leitura crítica sobre as possiblidades de interação e participação estabelecidas pela segunda tela, foram analisados três episódios do reality show The Voice (Estados Unidos). A partir dos dados aferidos, discutem-se os principais pontos que contribuem para o engajamento do público na Social TV.

Palavras-chave

Social TV, segunda tela, convergência midiática, The Voice, cultura participativa.

\section{Abstract}

Social TV is transforming the audience metrics, the participation level of the interactors, the narrative structures, the viewer reception, and is bringing back the appointment television. The phenomenon shows that the current connectivity ecosystem does not represent the death sentence for the mass media, but an opportunity to catch up on the new multitasking habits of the viewers. In order to establish a critical view about the possibilities of interaction and participation established by the second screen, we analyzed three episodes of the reality show The Voice (US). From the measured data we discuss the main points that contribute to public engagement on Social TV.

\section{Keywords}

Social TV, second screen, media convergence, The Voice, participatory culture. 


\title{
Introdução
}

A relação intrínseca entre televisão e social media traz a premência de uma nova sala de estar. Na Social TV, o watercooler ${ }^{3}$ é transportado para a instantaneidade do Twitter, o appointment televison ${ }^{4}$ se transforma em uma grande comunidade online, e a relação entre produtores e telespectadores ganha configurações inéditas. O fenômeno se refere à utilização das redes sociais, em especial o Twitter, de maneira síncrona à programação televisiva, e marca a simbiose entre a televisão e a Web 2.0 (PROULX; SHEPATIN, 2012). Mesmo sendo considerada uma prática emergente, a Social TV parte de hábitos culturais e de consumo já estabelecidos. Conforme aponta Lemos (2013):

\begin{abstract}
A evolução das mídias digitais tem levado a um retorno a experiências consagradas com as mídias de massa. Elas aportam novidades consideráveis, mas estão buscando, de certa maneira, um retorno a experiências passadas, ancoradas nos hábitos culturais estabelecidos. As análises sobre as novas mídias centraram-se nas diferenças, na morte dos antigos formatos e na superação da experiência analógica com o surgimento do digital e das redes telemáticas. Mas as práticas atuais mostram que estamos assistindo a um retorno a experiências muito similares às anteriores, com o aproveitamento das inovações sociais e tecnológicas do digital, principalmente no que se refere às possibilidades de produção de conteúdo de compartilhamento de informação e de criação de redes sociais (p. 146).
\end{abstract}

O autor afirma que este retorno pode ser observado nas mídias de geolocalização, no cinema, na música, nos livros e na televisão. Este é o caso da Social TV. Mesmo inaugurando uma nova experiência televisiva, o fenômeno resgata elementos que sempre fizeram parte do meio: o conceito de watercooler e a experiência coletiva. Wolton (1996) afirma que a televisão é um meio social, as interações durante a exibição dos programas fazem parte do seu modo de recepção. Os comentários com os amigos, com os familiares e com os colegas de trabalho constituem um grau amplo e socialmente difundido. 
Na chamada TV em duas telas o público tem a oportunidade de comentar a programação televisiva não só com as pessoas que estão fisicamente próximas a ele, mas também com inúmeros interlocutores nas redes sociais. Além de dispor de uma temporalidade always on ${ }^{5}$, a arquitetura informacional do Twitter, plataforma mais utilizada pelos interagentes ${ }^{6}$ multitasking $^{7}$, não é baseada em vínculos preexistentes (SANTAELLA; LEMOS, 2010). Ou seja, a interação entre os usuários não é motivada apenas pelos relacionamentos familiares, de amizade ou profissionais, mas por interesses em comum. Desta forma, o feed de informações da rede social se torna mais dinâmico do que, por exemplo, no Facebook. Já que no microblog o que importa não é a ligação afetiva que os usuários têm uns com os outros, mas o conteúdo de suas postagens. Por isso o Twitter faz com que os comentários sobre programação televisiva, que antes se esvaneciam entre as paredes da sala de estar, atinjam uma escala planetária, e não circulem apenas entre um grupo restrito de interagentes.

A utilização das hashtags também contribui para o dinamismo do backchanne/ ${ }^{8}$. Além de unificar o $b u z z^{9}$, a tagueação permite que os usuários acompanhem e participem das discussões em torno de um assunto específico, mesmo não "seguindo" uns aos outros. É a partir das hashtags que se formam as comunidades de ocasião. Segundo Bauman (2003), essas comunidades são "autoconstruídas em torno de eventos, ídolos, pânicos ou modas" (p. 51). Ao incluir a hashtag que faz alusão ao programa em questão, o usuário do Twitter

5 Característica das redes sociais 3.0 - Twitter, Facebook -, em que "a conexão é tão contínua a ponto de se perder o interesse pelo que aconteceu dois minutos antes. Apenas o movimento do agora interessa" (SANTAELLA; LEMOS, 2010, p. 62). relação) que acontece entre participantes". 
integra, automaticamente ${ }^{10}$, o feed de comentários referentes ao assunto, tornando o backchannel mais pluralizado e dinâmico.

A experiência coletiva também ganha novas possibilidades na Social TV. De acordo com Wolton (1996), a televisão tem o poder de reunir indivíduos de distintas camadas sociais em torno de uma atividade simultânea e é peça fundamental no compartilhamento de uma esfera pública de debates e na formação de laços sociais. A TV dá ao público uma sensação de pertencimento, como se ele fizesse parte, mesmo que momentaneamente, de uma comunidade, formando o que Wolton (1996) define como laço social.

Em que a televisão constitui um laço social? No fato de que o espectador, ao assistir a televisão, agrega-se a esse público potencialmente imenso e anônimo que assiste simultaneamente, estabelecendo assim, como ele, uma espécie de laço invisível (p.124).

A televisão tem o poder de pautar assuntos no dia-a-dia dos telespectadores. Desde temas mais complexos até os acontecimentos das telenovelas, séries de TV, talk shows, tudo é discutido pelo público. Na Social TV essa esfera debate ganha escala planetária e se propaga instantaneamente.

Os usuários do Twitter não só compartilham suas impressões, mas produzem conteúdos relacionados aos programas que estão sendo exibidos. Conforme Borges (2013) o fenômeno "[...] permite que os telespectadores atuem como interatores, uma vez que não apenas assistem, mas também produzem conteúdos que são disseminados nas redes sociais". Como exemplo, os fãs das tramas Game of Thrones (2011), Pretty Little Liars (2010) e The Walking Dead (2010), durante a exibição dos episódios, produzem e postam releituras, memes e montagens sobre as cenas. Essa forma de se relacionar com o conteúdo afasta o meio do lean-back ${ }^{11}$ e faz com que a experiência televisiva se torne mais participativa. 


\section{Reality show: um gênero híbrido}

Considerado um dos primeiros formatos bem sucedidos dentro da convergência midiática (CASTRO, 2006; FECHINE, 2009), o reality show integra o âmbito televisivo estadunidense há algum tempo. Segundo Mateus (2012), em 1948, o programa Candid Camera já esboçava o gênero ao exibir reações de pessoas comuns perante situações provocadas pelos membros da produção. Posteriormente, em 1973, a emissora PBS levou ao ar o primeiro reality show: An American Family. O programa acompanhava os percalços de uma família burguesa ao enfrentar o divórcio. No mesmo ano, o The Family mostrava a rotina de uma típica família britânica, os Wilkins.

Classificado como um gênero híbrido (CASTRO, 2006), o reality show representa a multiplicidade de vários formatos, que juntos resultam na estética de programas como Big Brother (1999), Survivor (Estados Unidos) (2000), American Idol (2002), Extreme Makeover (2003) e Top Chef (2006). Conforme aponta Mateus (2012), "O formato reality show prima pela confluência e intersecção de múltiplos gêneros televisivos integrando, compondo e readaptando os elementos constituintes de outros gêneros como, por exemplo, o documentário, a competição, ou o talk show ${ }^{12 "}$ (tradução nossa). (p. 377).

Johnson (2012) defende que o ambiente de convergência traz novas possibilidades aos reality shows. De acordo com o autor, o formato está se aproximando da estrutura dos games, pois sua linha narrativa é construída durante sua execução.

\footnotetext{
As regras e as convenções do gênero dos realities shows estão em constante instabilidade, e essa imprevisibilidade é parte do seu atrativo. Essa é uma das diferenças cruciais entre os realities shows e seus antecessores, os programas de pergunta e resposta (Ibid., p. 76).
} 
Outra característica que é potencializada no atual ecossistema de conectividade é a participação do público. Segundo Fechine (2009), os desdobramentos do reality são orientados conforme a vontade dos telespectadores. Em atrações como Big Brother e American Idol o público tem a possibilidade de "interferir diretamente no programa, passando a consumir uma narrativa cujo desenvolvimento depende também da sua atuação" (p. 10). No âmbito da segunda tela ${ }^{13}$, o gênero se destaca não só por estabelecer novas formas de interação, mas por potencializar a participação dos telespectadores.

\section{The Voice e as franquias de consumo}

Consolidado como uma franquia coerente aos parâmetros de imersão da cultura da convergência e bem sucedida entre as produções da Post-Network Television (PROULX; SHEPATIN, 2012), o reality show The Voice fez sua estreia no canal estadunidense NBC em 2011. Criado pelo produtor John de Mol, o programa é baseado na competição musical The Voice of Holland. Com formato de coaching por parte do júri, composto por músicos e produtores, a atração cumpre quatro etapas: a primeira trata-se de audições às cegas, a segunda é formada pela batalha entre os vocalistas, na terceira os competidores disputam a preferência do público, e na quarta temos a rodada final entre os finalistas. Durante todo o processo os cantores são acompanhados por seus tutores, que são membros do júri ${ }^{14}$.

No ar atualmente em sua sexta temporada na TV estadunidense, o reality da NBC tem também suas versões em outros países, como: Albânia, Kosovo, Macedônia, Argentina, Austrália, Bélgica, Brasil, Bulgária, Canadá, Chile, República Tcheca, Eslováquia, China, Colômbia, Dinamarca, Finlândia, França, Alemanha, Grécia, Hungria, Índia, Indonésia, Irlanda, Israel, Itália, Japão, Lituânia, México, Holanda, Noruega, Filipinas, Polônia, Portugal, Romênia, 
Coreia do Sul, Espanha, Suécia, Suíça, Tailândia, Turquia, Ucrânia, Reino Unido e Vietnã (PARMEGGIANI, 2013). Intitulado The Voice Brasil, a versão nacional da competição estreou em 2012 e se consolidou rapidamente na grade da Rede Globo. A reportagem, publicada pela Folha de São Paulo em 27 de novembro de 2013, destaca os índices de audiência alcançados pelo reality show do canal.

Na semana de 4 a 10 deste mês o The Voice Brasil teve o terceiro maior público da emissora em SP, com 26 pontos (cada ponto equivale a 62 mil domicílios da Grande SP), média que mantém desde a estreia, atrás de Amor à Vida (37) e à frente do Jornal Nacional (25) (LIMA, 2013).

O êxito do gênero no ambiente de convergência se dá, em parte, pela maneira que o conteúdo é explorado. Jenkins (2008) afirma que os reality shows da Post-Network Television vão além do formato televisivo, criando vários pontos de acesso. As franquias transmídia não se esgotam em uma plataforma; pelo contrário, novas camadas narrativas são apresentadas ao público, garantindo, assim, a expansão do conteúdo. No caso de The Voice, durante o período em que o programa está no ar são lançadas várias vias de consumo do reality como, por exemplo, músicas, vídeo clipes, revistas e aplicativos. Após o encerramento da temporada, o público ainda pode assistir às turnês realizadas pelos vencedores da atração.

Desta forma, cada temporada do reality show gera cadeias de consumo que tem como gênese a TV, mas se perpetuam por anos nas mais distintas linguagens midiáticas. Nicolle Yaron, produtora do reality, afirma que

A história de The Voice não é apenas uma ou duas horas por semana. Ela se mantém durante todo o dia e durante toda a semana, e vai perpetuar durante todo o ano. É uma experiência imersiva, não uma exposição fugaz ${ }^{15}$ (THE VOICE, 2011, tradução nossa).

Apesar de ser configurado pela participação do público, que manifesta sua vontade pelos votos, o gênero ganhou uma nova dinâmica no ecossistema 
da Social TV. Proulx e Shepatin (2012) pontuam que o The Voice foi pioneiro ao estimular o compartilhamento de impressões no Twitter, tanto dos telespectadores quanto dos integrantes da atração. Além de divulgar hashtags exclusivas e criar ações voltadas para a segunda tela, o grande fio condutor das estratégias da emissora no âmbito da TV em duas telas é o poder que as celebridades exercem no microblog. Na edição atual ${ }^{16}$, os artistas Adam Levine, Shakira, Usher e Blake Shelton não só interagem com o público estadunidense, como também mobilizam seus fãs de outras partes do mundo a assistirem ao programa e postarem suas opiniões no Twitter. Neste cenário, o telespectador tem a oportunidade de comentar a atração em tempo real com os jurados, dinâmica essa que só se configura no ambiente da Social TV.

\begin{abstract}
A experiência coletiva, a dinâmica de conectividade e a comunidade de fãs eram os princípios básicos da estratégia de social media do programa. Seu objetivo era criar uma experiência imersiva em tempo real que permitisse que todos os telespectadores se sentissem parte do reality ${ }^{17 " \prime}$ (PROULX; SHEPATIN, 2012, p. 22, tradução nossa).
\end{abstract}

A fruição do backchannel também se estende pelos países em que o reality é exibido. A versão nacional do The Voice atingiu, durante a estreia de sua segunda temporada em 3 de outubro de 2013, um pico de 7,5 mil tuítes por minuto (THE VOICE, 2013). Apesar de ter estreado recentemente, o programa já é um grande marco da Social TV no Brasil.

\footnotetext{
O reality show musical The Voice Brasil, também exibido pela Rede Globo, foi considerado o "Rei do Twitter" em 2013, de acordo com a plataforma analítica TTV, que acompanha a interação entre televisão e mídias sociais. O programa, em sua segunda edição no país, foi o conteúdo televisivo que gerou a maior atividade naquela mídia social no ano: foram aproximadamente 650 mil comentários, que impactaram mais de dois milhões de usuários de Twitter (CAMPANELLA, 2014, p. 11).
}

16 Exibida nos Estados Unidos entre 24 de fevereiro de 2014 a 21 de maio de 2014.

17 "On-air talent accessibility, openness, community, and connection we're all tenets of the show's social media strategy. Their goal was to create a real-time viewing experience that allowed spectators to become and feel as though they were part of the show". 
Para o desenvolvimento deste artigo, o reality show foi monitorado durante três semanas, nos quais se observou o número de tuítes gerados durante a exibição do programa e as ações desenvolvidas pelo canal estadunidense NBC para fidelizar os telespectadores.

\section{A legitimação do backchannel}

Para a estreia da sexta temporada de The Voice, a NBC preparou uma ação com os jurados Adam Levine e Blake Shelton. Durante a première, exibida em 24 de fevereiro de 2014, os artistas assumiram um a conta do outro no Twitter. Segundo dados divulgados pela Nielsen (2013), a estratégia da emissora para aumentar o buzz teve um saldo positivo. No perfil de Adam (@adamlevine) - assumido momentaneamente por Blake - os 18 tuítes postados durante o programa geraram 69.721 retuítes e 54 mil novos seguidores. Já a conta de Blake (@blakeshelton) - assumida momentaneamente por Adam - postou 21 vezes, conquistando 41 mil novos seguidores e 42.894 retuítes no microblog. 0 canal também realizou uma parceria com o Get Glue e divulgou uma hashtag específica (\#VoicePremiere) enquanto a competição estava no ar. A conta do canal no Twitter (@NBCTheVoice) motivou os usuários postando 301 vezes durante a estreia de The Voice. Todo o investimento gerou um buzz de 329,7 mil tuítes, que atingiram 16,657 milhões de usuários (NIELSEN, 2014a). Na TV, a estreia das audições às cegas foi assistida por 15,86 milhões de espectadores, com 4,7 de rating (TV BY THE NUMBERS, 2014a). Para a produtora da atração Nicolle Yaron, ao criar uma nova relação entre o público e os jurados a Social TV faz do appointment television uma experiência única, pois os fãs têm a oportunidade de comentar o programa com os seus ídolos, e muitas vezes a discussão vai além do que é apresentado na televisão. Isso contribui para a prolongação da franquia e da experiência televisiva. "Continuamos contando histórias e enriquecemos a experiência dos telespectadores, mesmo quando não estamos no $\operatorname{ar}^{18 "}$ (THE VOICE, 2011, tradução nossa). 
Exibido um dia após a estreia da sexta temporada de The Voice, o episódio The Blind Auditions, Part 2 gerou 102,2 mil comentários no Twitter e atingiu 13,04 milhões de usuários da rede social (NIELSEN, 2014b). Para motivar os tuítes síncronos à atração, a NBC postou 124 vezes em seu perfil no microblog e manteve a parceria com o Get Glue. Os usuários que realizassem check-in enquanto o reality estivesse no ar desbloqueariam um adesivo virtual exclusivo. Para unificar o buzz e aumentar a propagação do conteúdo, a emissora também lançou a hashtag \#BlindsContinue, que fazia alusão ao arco do episódio. Segundo dados do TV by the Numbers (2014b), o programa, exibido no dia 25 de fevereiro de 2014 , foi assistido por 12,97 milhões de telespectadores com rating de 3,7.

Para o episódio The Blind Auditions, Part 3 a NBC manteve sua parceria com o Get Glue e a hashtag \#BlindsContinue. No perfil no canal no Twitter foram postados 141 tuítes durante a exibição de The Voice. A ação gerou um buzz de 104 mil impressões, atingindo 12,155 milhões de usuários no dia 3 de março de 2014 (NIELSEN, 2014c). O terceiro episódio da sexta temporada do reality musical também foi visto por 15,62 milhões de telespectadores, com um rating de 4,5 (TV BY THE NUMBERS, 2014c).

A eficácia de The Voice no âmbito da Social TV não é acaso. O reality show reúne três pontos importantes do fenômeno: (1) a experiência coletiva dos programas ao vivo, (2) a capacidade de mobilização das celebridades nas redes sociais e (3) a coerência das ações realizadas pela emissora.

Segundo Mateus (2012), uma das chaves para o sucesso dos reality shows é a experiência coletiva ser praticamente obrigatória, ou seja, os episódios só fazerem sentido se assistidos no momento real da transmissão. Por isso o gênero vem atingindo índices de audiência equiparáveis a outros grandes eventos televisivos.

[...] que os reality shows batem, em todo o mundo, recordes históricos de audiência. Números que até então eram atingidos apenas durante grandes eventos televisivos como: Copa do Mundo, funerais da família real ou Olimpíadas (MATEUS, 2012, p. 375, tradução nossa). 
A mobilização da audiência integra o formato de tal forma que Biressi e Nunn (2005) propõem classificar os reality shows como Event-TV ${ }^{19}$. Segundo os autores, o conceito se refere a um programa que "atrai um público enorme e torna-se parte do discurso popular sobre a vida cotidiana20" (p. 11, tradução nossa).

Conforme defendem Proulx e Shepatin (2012), a Social TV se configura quando os sujeitos midiáticos postam comentários síncronos à exibição de um programa ou evento televisivo. Desta forma, o backchannel de The Voice já parte de um ambiente favorável ao fluxo elevado de tuítes. Afinal, não faz sentido para o telespectador assistir o reality show depois de sua exibição, pois a experiência televisiva deste gênero é pautada por sua fatualidade. Enquanto as narrativas seriadas ficcionais têm que arquitetar uma dinâmica única e atrativa para trazer o público de volta para TV com hora marcada, o The Voice apresenta um formato que já configura o hábito naturalmente. Somado ao seu appointment television quase que obrigatório, temos a estrutura informacional do Twitter que propicia o compartilhamento instantâneo de informações. Na rede social, apenas o imediato faz sentido. Esses dois elementos fazem com que o buzz de The Voice atinja uma média superior às séries consagradas da TV estadunidense como How I Met Your Mother (2005), Game of Thrones (2011) e Grey's Anatomy (2005). O êxito dos eventos ao vivo no fenômeno não se restringe apenas ao gênero dos reality shows; premiações e competições esportivas também estão entre as atrações mais comentadas da Social TV (ADASHEK,2014).

Outro ponto que contribui para o buzz de The Voice é o poder de influência e mobilização que os jurados exercem no Twitter. Baym (2013) afirma que o uso das redes sociais pelos músicos é uma das tentativas de sobrevivência da indústria fonográfica no âmbito da convergência midiática. A Web 2.0 oferece a possibilidade, até então inédita, aos artistas de se conectarem aos seus fãs. Se antes as raras oportunidades de troca de informação entre o ídolo e seu público 
aconteciam depois de um show ou durante o lançamento de um álbum, nas redes sociais essa relação ganha uma nova dinâmica.

Ao invés de engajar audiências apenas através de mídia de transmissão e performances ao vivo com papéis sociais altamente restritos, artistas performáticos agora têm uma chance maior de encontrá-los como indivíduos com os quais eles podem ter interações contínuas online (BAYM, 2013, p. 18).

$\mathrm{Na}$ arquitetura informacional do Twitter essa conexão se potencializa, pois os fãs tem a oportunidade de contatar seus ídolos com mais frequência e acompanhar, mesmo que ilusoriamente, seu dia a dia e suas opiniões, encurtando assim a distância entre eles. Porém, o espectro de interação do microblog não é benéfico apenas para o público, já que na plataforma as celebridades podem se desprender dos grandes meios de comunicação para divulgar seu trabalho e estabelecer uma relação de proximidade com os usuários.

O Twitter também destrói a expectativa da parassocialidade entre a pessoa famosa e o fã. $O$ estudo da cultura de celebridade tem focado principalmente em fãs separadamente da celebridade, mas a habilidade de pessoas famosas em ler e responder aos fãs deu início a uma nova série de práticas e interações. Celebridades precisam aproveitar dessa habilidade para manter afiliações constantes e conexões com seus fãs, ao invés de parecerem indiferentes ou indisponíveis. E assim, o Twitter cria uma nova expectativa de intimidade (BAYM apud MARWICK; BOYD, 2013, p. 42).

As séries de TV, ao contrário, arquitetam uma estratégia para migrar os produtores e os atores para o Twitter e, posteriormente, estabelecer a conexão entre o público e as celebridades, como foi o caso de Scandal. Com os músicos todo esse processo já se dá desde 2010 (BAYM, 2013). Há quatro anos eles vêm firmando uma relação de proximidade com os usuários da plataforma. Por isso The Voice consegue tamanha mobilização em seu backchannel. O poder mobilização de fluxo das celebridades (SANTAELLA; LEMOS, 2010) é incorporado a uma base de seguidores de longa data.

No reality show da NBC, essa relação entre o público e os músicos se materializa de várias formas. Mesmo não fazendo parte de sua campanha 
de Social TV, a emissora inclui em suas postagens no Twitter as hashtags lançadas pelas fanbases dos jurados. Intitulados "teams", cada grupo de fãs tem uma indexação específica para representar o apoio ao jurado de sua preferência. Nesta temporada de The Voice temos o \#teamadam, \#teamshakira, \#teamusher e \#teamblake. Além de motivar os comentários síncronos à exibição do programa, as hashtags estimulam uma competição saudável entre os fãs, que disputam qual time está se saindo melhor no reality e nos trending topics da rede social.

A capacidade de mobilização de Adam Levine, Shakira, Usher e Blake Shelton é tão forte que faz com que o appointment television ultrapasse o território estadunidense. Mesmo sem ter a NBC em sua grade de programação, fãs de várias partes do mundo assistem ao programa durante a sua exibição apenas para reforçar a torcida pelo seu ídolo. O fã clube brasileiro da banda Marron 5 (@maroon5br), na qual Adam Levine é vocalista, divulga para seus seguidores o link do streaming ${ }^{21}$ da emissora e os convida a comentar o The Voice e, é claro, torcer. Ao longo da exibição, o perfil @maroon5br vai trocando informações com outros usuários e apoiando as decisões tomadas por Adam no reality show. O poder de mobilização das celebridades também se estende aos competidores do programa, que ao decorrer do reality constroem sua própria fanbase no microblog.

Por fim, deve-se considerar a estratégia realizada pela NBC para motivar o backchannel. A cada temporada a emissora desenvolve novas formas de interação no Twitter e explora as potencialidades do fenômeno focando não só no buzz, mas na experiência televisiva dos participantes. O conceito de engajamento adotado pelo canal vai além das hashtags específicas e do incentivo aos comentários síncronos, e configura uma nova dinâmica no âmbito na TV em duas telas. 
Lançado em novembro de 2013, o Instant Save 22 traz para o Twitter o poder de decisão do público. Por ser um elemento de fácil mineração, os votos são computados por meio de hashtags personalizadas. Ao postar a \#instantsave juntamente com primeiro nome do competidor, o público votará na permanência do participante no programa. Além de ser uma ação inédita ${ }^{23}$ na Social TV, o Instant Save proporciona aos usuários da rede social um poder de decisão que até então era restrito aos jurados do programa.

Durante o programa de hoje à noite, seu tweet "Instant Save" durante a transmissão ao vivo irá determinar o destino dos competidores. Anteriormente, apenas treinadores de The Voice tinham o poder de salvar o participante. Agora, usando o Twitter enquanto assiste ao programa, o poder é seu²4 (TWITTER, 2013, tradução nossa).

Ao permitir que os telespectadores participem exclusivamente pelo microblog, a NBC estimula não só o backchannel, mas reconhece o poder que a Web 2.0 exerce sob a televisão contemporânea.

O engajamento do interagente multitasking não se dá de forma aleatória; o elo entre a televisão e o Twitter se materializa nas características narrativas do programa. Ao explorar as potencialidades do The Voice, a NBC comprova que cada gênero televisivo repercute de uma maneira distinta na Social TV. Ao invés de limitar-se às ações básicas do fenômeno ou deixar que apenas os jurados motivem os telespectadores a compartilharem suas impressões, o canal faz do watch and tweet ${ }^{25}$ uma experiência única e imersiva. Ao transpor o watercooler Twitter. Porém, o recurso não era exclusivo da plataforma, os telespectadores também podiam participar por SMS e enquete no site (HERNANDEZ, 2011). broadcast. Previously, only coaches on The Voice had the power to make a save. Now, using Twitter as a real-time public platform in conjunction with a live TV broadcast, the power is yours." 
para o ciberespaço e abrir novas janelas de participação, o reality show mantém seu legado de inovação no ambiente de convergência.

\section{Considerações finais}

A partir da mineração de dados da Nielsen e do monitoramento das estratégias do canal NBC, conseguiu-se fundamentar os principais elementos responsáveis pelo engajamento, participação e interação dos interagentes multitasking de The Voice. Isso mostra a forma que a Social TV resgata a experiência coletiva, o appointment television, e cria uma relação mais participativa e complexa com os telespectadores.

Como observamos, as ações de engajamento da NBC são direcionadas de acordo com os desenhos de produção do reality show, mostrando que os 140 caracteres do Twitter são apenas o ponto de partida para uma gama de janelas imersivas. A Social TV vai além dos comentários síncronos à programação e altera a experiência televisiva, desde a sua recepção até a interação.

A segunda tela renova as possibilidades de participação e colaboração nos reality shows, na qual o público tem a oportunidade de compartilhar suas impressões não só com outros interagentes, mas com os jurados do programa. O backchannel deixa de ser apenas um ambiente de conversação e passa a interferir nos rumos da competição. Para integrar à comunidade de ocasião que se forma durante a exibição de The Voice, fãs do mundo todo se voltam para frente da TV e mostram que a experiência televisiva contemporânea já estabeleceu uma relação intrínseca com as redes sociais. 


\section{Referências}

ADASHEK, A. Nielsen reveals the TV season's top shows on Twitter. Nielsen, 2 jun. 2014. Disponível em: <http://goo.gl/8nJ80g>. Acesso em: 3 jun. 2015.

BAUMAN, Z. Amor líquido: sobre a fragilidade dos laços humanos. Rio de Janeiro: Jorge Zahar, 2003.

BAYM, N. K. Fãs ou amigos? Enxergando a mídia social como fazem os músicos. Matrizes, São Paulo, v. 7, n. 1, p. 13-46, 2013. Disponível em: <http://goo. gl/8EwMjm>. Acesso em: 9 jun. 2015.

BIRESSI, A.; NUNN, H. Reality TV- realism and revelation. Londres: Wallower Press, 2005.

BORGES, G. Social TV: Discussões preliminares sobre o fenômeno. Colóquio Internacional Em Mídia Digital - Televisão E Interatividade, 1, Juiz de Fora-MG. Anais... Juiz de Fora: UFJF, 2013. CD-ROM.

CAMPANELLA, B. Novas práticas, antigos rituais: a organização do cotidiano e as configurações de poder na mídia. Revista GEMInIS, Edição Especial, p. 8-12, maio 2014. Disponível em: <http://goo.gl/kfZHOp>. Acesso em: 8 jun. 2015.

CASTRO, C. Por que os reality shows conquistam audiências? São Paulo: Paulus, 2006.

FECHINE, Y. A programação da TV no cenário de digitalização dos meios: configurações que emergem dos reality shows. In: FREIRE FILHO, J. (Org.). A TV em transição: tendências de programação no Brasil e no mundo. Porto Alegre: Sulina, 2009. p. 139-170. 
GRAVER, F. Tweet to "save" artists on NBC's The Voice. Twitter. 12 nov. 2013. Disponível em: <https://goo.gl/xRDgTO>. Acesso em: 10 jun. 2015.

HERNANDEZ, B. A. Twitter now lets "X Factor" viewers vote via DMs. Mashable, 26 out. 2011. Disponível em: <http://mashable.com/2011/10/26/xfactortwitter-vote-dm-direct-messages/>. Acesso em: 18 mai. 2015

JENKINS, H. Cultura da convergência. 2. ed. São Paulo: Aleph, 2008.

JOHNSON, S. Tudo que é ruim é bom para você: como os games e a TV nos tornam mais inteligentes. Rio de Janeiro: Zahar, 2012.

LIMA, I. 'The Voice Brasil' vira hit na TV e na web; produtores criticam estilo pasteurizado. Folha de São Paulo, 2013. Disponível em: <http://m.folha.uol. com.br/ilustrada/2013/11/1376806-the-voice-brasil-vira-hit-na-tv-e-na-webprodutores-criticam-estilo-pasteurizado.shtml?mobile>. Acesso em: 27 nov. 2015.

LEMOS, A. A comunicação das coisas: teoria ator-rede e cibercultura. São Paulo: Annablume, 2013.

MARWICK, A; BOYD, D. To see and be seen: celebrity practice on Twitter. Convergence: The International Journal of Research into New Media Technologies, v. 17, n. 2 , p. $139-158,2011$.

MATEUS, S. Reality-show: ascendências na hibridização de gênero. Contemporânea: Comunicação e Cultura, v. 10, n. 2, p. 374-390, 2012. Disponível em: <http://goo.gl/pSn5Io>. Acesso em: 7 jun. 2015.

NIELSEN Twitter TV ratings 24/02/2014. Nielsen, 2014a. Disponível em: < http://goo.gl/cxtZgM>. Acesso em 25 fev. 2015. 
NIELSEN Twitter TV ratings 25/02/2014. Nielsen, 2014b. Disponível em: < http://goo.gl/kCdl5T >. Acesso em 26 fev. 2015.

NIELSEN Twitter TV ratings 03/03/2014. Nielsen, 2014c. Disponível em: < http://goo.gl/qTCZ4P >. Acesso em 04 mar. 2015.

PARMEGGIANI, B. S. A relação dos media tradicionais com as audiências através das redes sociais online - um estudo de caso da participação dos telespectadores nos programas The Voice, A Voz de Portugal e The Voice Brasil. 2013. Dissertação (Mestrado em Ciências Sociais e Humanas). Faculdade de Ciências Sociais e Humanas, Universidade Nova de Lisboa, Lisboa, 2013. Disponível em: <https:// goo.gl/iVZBwU>. Acesso em: 5 jun. 2015.

PRIMO, A. Quão interativo é o hipertexto?: da interface potencial à escrita coletiva. Fronteiras: Estudos Midiáticos, São Leopoldo, v. 5, n. 2, p. 125-142, 2003.

PROULX, M.; SHEPATIN S. Social TV - how marketers can reach and engage audiences by connecting television to the web, social media, and mobile. Nova Jersey: John Wiley \& Sons Inc., 2012.

SANTAELLA, L.; LEMOS, R. Redes sociais digitais: a cognição conectiva do Twitter. São Paulo: Paulus, 2010.

THE VOICE Brasil vira hit na TV e na Web; produtores criticam estilo pasteurizado. Folha de São Paulo, 27 nov. 2013. Disponível em: <http://goo.gl/npgu95>. Acesso em: 8 jun. 2015.

THE VOICE: how a TV show became a $24 / 7$ social media conversation. Mashable, 2011. Disponível em: <http://mashable.com/2011/06/15/the-voice-socialmedia-nbc/\#5RkatgqJi8qP>. Acesso em: 8 jul. 2014. 
TV BY THE NUMBERS. Monday final ratings: 'The Bachelor' adjusted up; no adjustment for 'Almost Human' or 'Star Crossed', 25 fev. 2014a. Disponível em: <http://goo.gl/Uw8Qcl>. Acesso em: 26 fev. 2015.

. TV Ratings Tuesday; 'NCIS' \& 'Person of Interest' hit lows, 'Glee' rises + 'Mind Games' has soft Debut, 26 fev. 2014b. Disponível em: <http:// tvbythenumbers.zap2it.com/2014/02/26/tv-ratings-tuesday-ncis-personof-interest-slide-supernatural-rises-mind-games-has-soft-debut/240319/>. Acesso em: 25 nov. 2015.

Monday final TV ratings: 'The Bachelor' adjusted up; 'The Following' adjusted down, 4 mar. 2014c. Disponível em: <http://goo.gl/F3z8ZZ>. Acesso em: 5 mar. 2015.

WOLTON, D. Elogio do grande público - uma teoria crítica da televisão. São Paulo: Ática, 1996.

submetido em: 10 jul. 2015 | aprovado em: 10 ago. 2015 